\title{
Automated stand for the study of injectors made of polymer materials for hydraulic weed destruction
}

\author{
Dmitriy Khort ${ }^{1, *}$, Alexander Shutenko ${ }^{1}$, Rostislav Filippov ${ }^{1}$, and Stepan Semichev ${ }^{1}$ \\ ${ }^{1}$ Federal Scientific Agroengineering Center VIM, 1-st Institutsky proezd, 5, Moscow, 109428, Russia.
}

\begin{abstract}
The work describes a new technological process for weed destruction and tillage in the near-stem zones of fruit trees and covers the prospects for studying the hydraulic method of weed destruction. The quality of hydraulic tillage and weed destruction has been determined to be conditioned by the shape and the required pressure of the jet. The results of theoretical calculations and initial tests show that an automated stand is needed for nozzles' testing and optimizing the operating modes of the hydraulic device. A working body and an automated stand have been designed to study the parameters of nozzles made of polymer materials and the impact of the working body on various weeds and soil surfaces.
\end{abstract}

\section{Introduction}

An intensive technology for growing industrial gardens and berry-fields involves keeping the soil under the sodding of perennial grasses (green manure), entailing the tillage and the destruction of weeds in the near-stem zones [1]. Different methods are used to control weeds in the near-tree zones, such as mechanical, chemical, fire, hydraulic and pneumatic ones. All these methods are designed to raise the efficiency and affordability of the process. The disadvantages of the mechanical method include the high damage risks of the garden plantations and of the assemblage of rootlets. Moreover, the mechanical tillage involves the rise of the surface soil layer structure, which results in high risks of damage caused by spring frosts. The most widespread and efficient method of weed destruction is the chemical one. However, despite strict safety rules, the use of herbicides results in more drastic environmental risks of falling into different ecological chains and being accumulated in living organisms, as well as of disturbing inside soil biocenosis [2,3]. That is why, modern agricultural machinery and equipment designers pay great attention to the machines for nontoxic weeds destruction, which is associated with the transition to environmentally friendly (organic) agriculture. The evolution of these principles results in the construction of trailing devices using tractor energy appointed with gas or hydraulic equipment for tillage in rows of vineyards, berry-fields and in near-stem zones of fruit trees, using central water supply [4,5]. All the above-mentioned factors testify to the need for research of equipment for near-stem

\footnotetext{
* Corresponding author: vim_sad@mail.ru
} 
zone treatment, based on new operating methods. In this article, we have chosen the hydraulic method supposing the tillage with a jet of water under pressure, as the most optimal one. The Caffini Grass killer is regarded as the prototype machine. Its main drawback comprises the need for a complex and expensive pump of $1000 \mathrm{bar}$, with a flow rate of up to $100 \mathrm{l} / \mathrm{min}$. To reduce the required pressure of the pump and raise the quality of near-stem zones tillage, we propose polymer nozzles created by 3D printing. For further research to be conducted on the enhancement of this method by changing the nozzles' shape and optimizing he shape of the jet, we have elaborated a test method identifying the optimal parameters of the working body and its operating modes.

\section{Materials and methods}

The existing methods for the near-stem zones tillage having been analyzed, it is proposed to apply a hydraulic method, which means a high-pressure water jet treatment.This method entails the use of a rotating working head with two high-pressure nozzles (Fig. 1).

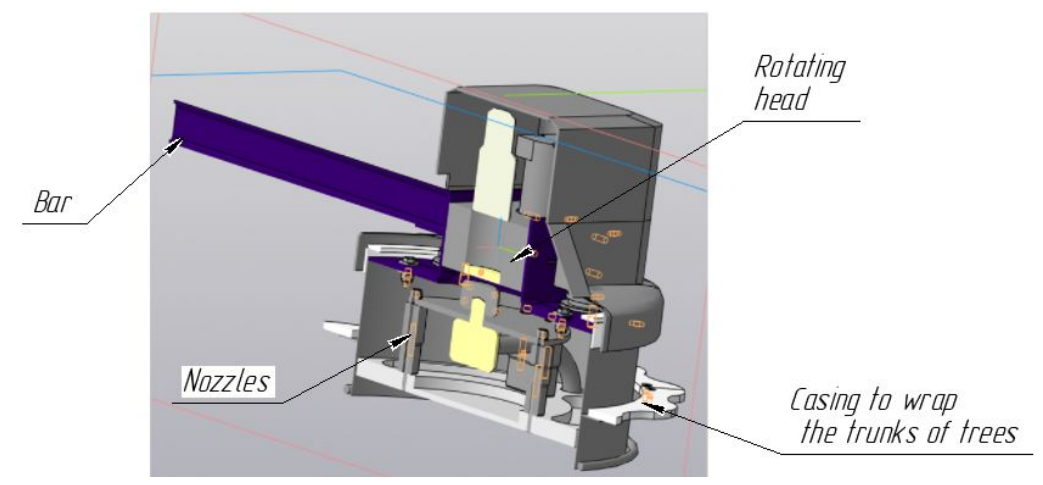

Fig. 1. The working head of the hydraulic treatment of the near-stem zones.

While being involved in the technological operation of weeds destruction, the rotary unit of the spray head is driven (rotated) by the tractor hydraulic system's engine. The pump of the machine provides a flow of liquid under high pressure going to the nozzles, which spray the working fluid and thus, produce a mechanical impact on weeds and soil. The pump pressure is regulated by the PTO rotation speed, maintained at a constant level from 500 to $600 \mathrm{rpm}$.

Vertical and horizontal adjustment of the spray head is carried out by double-acting hydraulic cylinders on the guide of the external section of the device. The spring on the guide allows to implement the near-stem zone treatment by bending (rotating) the spray head around the trunk and returning it to the working position after overcoming the obstacle. The working head is restrained in movement: it cannot move to a height of more than $600 \mathrm{~mm}$ from the supporting surface level; it cannot project into the lateral clearance for more than $700 \mathrm{~mm}$ from the starting position; the rotation angle relative to the supporting surface must not exceed $65^{\circ}$, the rotation angle relative to the longitudinal axe must not exceed $20^{\circ}$. The experience of other industries using water jets to produce impact on the surface has determined the design of nozzles for testing on soil: these are the point, the fan and the mud ones. The nozzles operate at a pump pressure of 150 bar and provide the pressure from 1 to 9 Bar on the soil surface (Fig. 2). 


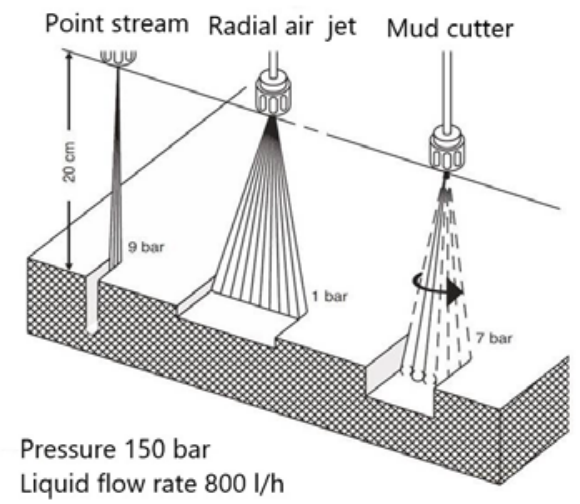

Fig. 2. Dependence of the jet's effect on the surface on the nozzle's shape (TIME KARCHER, 2009).

In order to justify the type of nozzles used, several practical initial tests were carried out: a high-pressure one-nozzle apparatus was used to wash complex fouling of off-road vehicles with the maximum pressure of 140 bar and the level of water consumption of $11.4 \mathrm{l} / \mathrm{min}$. A fan-shaped nozzle and a mud one were compared in the course of the research. The testing was carried out in Odintsovo district, Moscow region. The sod-podzolic type of soil was tested; the mechanical composition was the light loamy soil. The density of the soil came to $1.5 \mathrm{~g} / \mathrm{cm}$. The results are presented in figure 3.

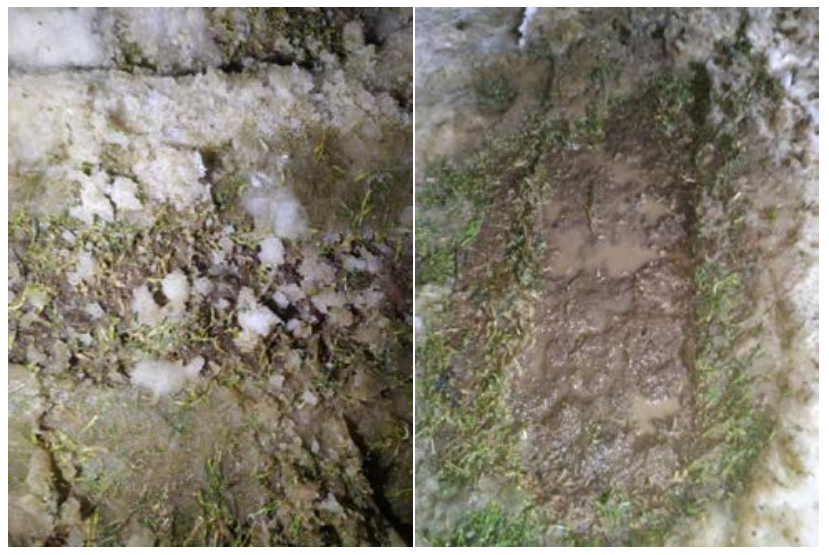

Fig. 3. Results of initial tests of different types of nozzles on the soil: on the left, the operation of the fan nozzle, - on the right, the operation of the mud mill.

The results of initial tests testify to the influence of the nozzle-formed jet shape, the inclination angle of the working head, the rotation speed and the height of the working head's location on the quality of tillage and the degree of weeds destruction. However, further research is needed to identify the optimal parameters of the working body and its operating modes, to determine and confirm the mathematical dependencies describing the operation of the apparatus while removing various types of weeds. We have designed a test method based on measuring the force effecting on the soil surface and allowing us to evaluate the quality of the work. Also, to optimize the operating conditions, it is necessary to control the movement speed of the working head, its inclination angle and the height of the working body. It would be optimal to conduct this set of tests with the usage of an automated stand capable of independently adjusting the above-mentioned parameters. For nozzles of various designs to be tested, we have proposed replacing metal nozzles with polymer ones. Sophisticated technological equipment is required in order to create metal nozzles, raising 
significantly their cost. Moreover, technological restrictions complicate the production of complex and efficient types of nozzles. We suggest using additive technologies based on SLA 3D printers to resolve this problem. This technology involves creating complex parts with high accuracy up to $0.01 \mathrm{~mm}$. At the same time, the necessary technological equipment is relatively cheap and more efficient (Fig. 4).
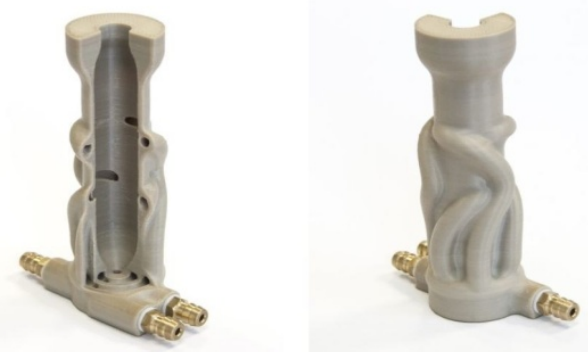

Fig. 4. An example of a polymer nozzle made by 3D printing.

\section{Results and discussions}

The designing conducted has resulted in the elaboration of an autonomous test stand SIA-1, consisting of a transparent container with samples of soil with a sod similar to the near-stem zones. The container with the soil is divided into two sections simulating two near-stem zones. At the base of this stand there are weight sensors designed to measure the force acting on the soil when the device is in operation. In the course of the measurement, the weight of the soil put in the container is taken into account first, as the reference point. When exposed to water streams, the force of the stream impact on the surface is measured according to changes in the weight recorded by the sensors. It is important to remember that while passing through the working body, the water is accumulated in the container. Therefore, it is important to take away the weight gained due to the liquid used in the tillage before processing the results. Transparent walls of the container allow to record the processes of weeds and top soil layer destruction (Fig. 5).

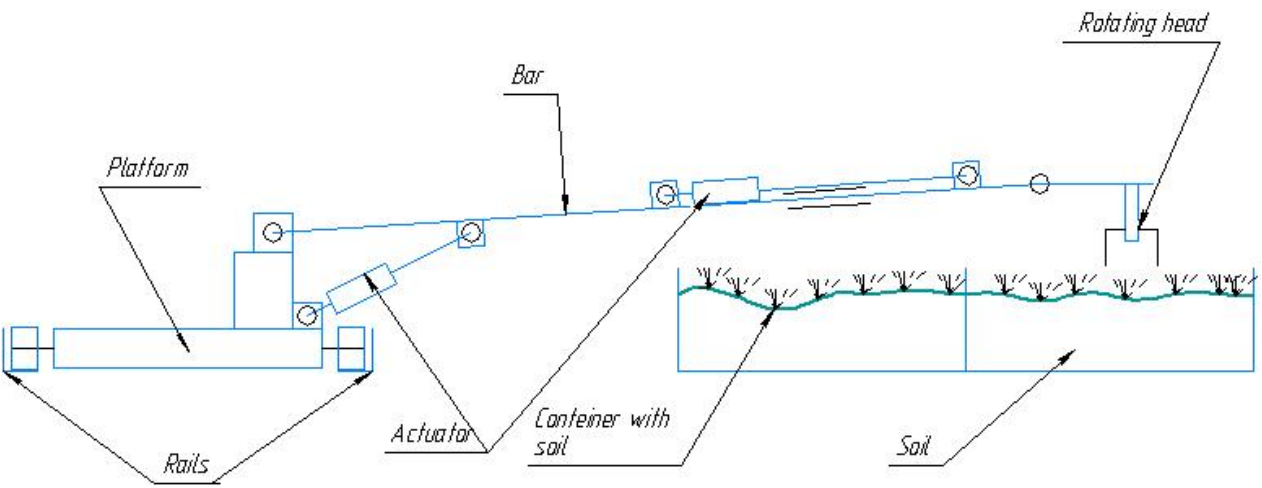

Fig. 5. Scheme of the test stand SIA.

The working body is fixed with the nozzles being located on the rotating head in parallel to its rotation axis and the adapters allowing to change the inclination angle of the nozzles in relation to the rotating head. The rotating head is fastened to a bar by a joint allowing to change the inclination angle of the head crosswise to the bar, while holding the head parallel to the soil surface. With the use of a linear actuator, the bar opens up allowing to move from 
one section to another. This device speeds up considerably the testing. The bar is attached to a mobile platform. The lifting height of the bar is regulated by a linear actuator guided by the control assembly. The mobile platform can move along the container with soil due to 4 polymer wheels. The wheels move along the guides. The guides are designed to be longer than the container to ensure the working body leaves the treatment zone. Guides are I-shaped. The frame of the mobile platform consists of square cross-section tubes. The mobile platform is set in motion by belt drive. The proposed drive of $200 \mathrm{~W}$ gives the opportunity to speed the platform up to $2.5 \mathrm{~m} / \mathrm{s}$ in 1 second, which corresponds to a $9 \mathrm{~km} / \mathrm{h}$ speed of the working body. The ends of the guides are made of a strong channel needed to stop the platform and are equipped with dampers from the car spring to dampen the impact energy. High pressure hoses for water supply are laid inside the hollow bar. The characteristics of the SIA are presented in table 1.

Table 1. Technical characteristics of the SIA

\begin{tabular}{|c|c|}
\hline Name of indicator & Indicators \\
\hline $\begin{array}{c}\text { Length of the container with } \\
\text { soil, mm }\end{array}$ & $990 \pm 5$ \\
\hline Section Width, mm & $450 \pm 5$ \\
\hline Soil layer height, mm & 200 \\
\hline Number of sections & 2 \\
\hline Container loading capacity, kg & 200 \\
\hline $\begin{array}{c}\text { Bar extension drive } \\
\text { Bar lift drive }\end{array}$ & $\begin{array}{c}\text { Linear actuator, } \\
100 \mathrm{~mm} / \mathrm{s}\end{array}$ \\
\hline $\begin{array}{c}\text { Linear actuator, } \\
100 \mathrm{~mm} / \mathrm{s}\end{array}$ \\
\hline gength of a mobile platform \\
guides, mm
\end{tabular}

This design allows to get a highly automated stand for testing various methods of tillage: with a jet of water under pressure, water jet method, pneumatic method, etc. To bring the stand to work, it is necessary to set the positions of the linear actuators and the rotation speed of the platform drive. To repeat the passage, the bar opens up automatically to the next section, the platform drive is launched in the opposite direction, the next section is treated. Soil exposure data registered by weight sensors is transmitted continuously to a computer for further processing. It is possible to record all the system data, such as the height of the working body, the section being treated, the speed of the platform. Moreover, the video recording may help evaluate the quality of tillage and the degree of weeds destruction (Fig. $6)$. 


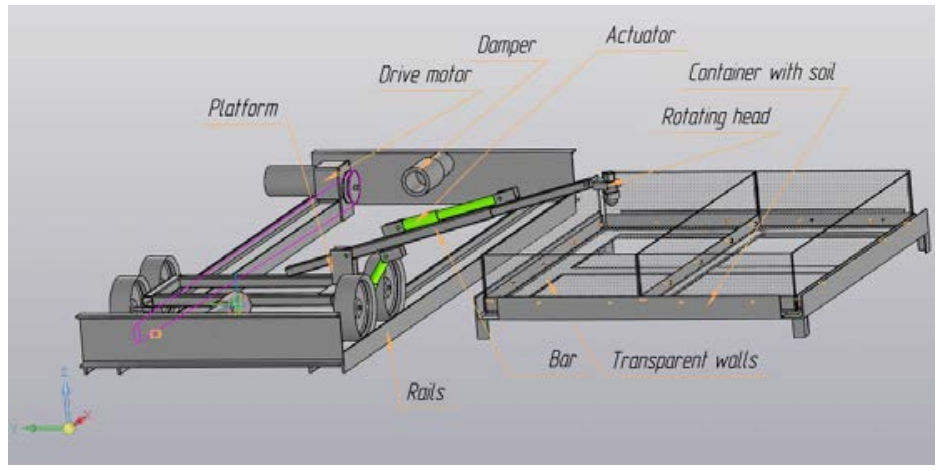

Fig. 6. 3D model of the designed stand.

For various types of nozzles and mouthpieces' testing, nozzles made by 3 D SIA printer are used. Nozzles are connected to each other through adapters, allowing to quickly change the test items. The SIA printing method allows to quickly and efficiently produce parts and modify their design. More than that, this method gives the possibility to quickly and efficiently produce nozzles of technologically complex shapes, with low labor costs, which will reduce the cost of their manufacturing.

\section{Conclusions}

The proposed method for hydraulic tillage allows complex testing of new methods of neartrunk zones treatment. Due to the high automation of the process, it is possible to carry out tests more often and obtain the most complete information about them. Another important factor of research automation is the use of polymer nozzles made by $3 \mathrm{D}$ printing, which speeds up the production of test samples and lowers its cost.

\section{References}

1. Krasovsky V.V. Justification of parameters and modes of operation of the mower for mowing cover crops between rows of orchards and vineyards. Academic work, 10-15. (2017).

2. Aminov A.I., The effect of the herbicide roundup on glycosidase fish and the objects of their power. Academic work, 3-4 (2018).

3. Abouziena H. F., Hagaag W. M. Weed Control in Clean Agriculture: A Review Planta Daninha. 34(2):377-392 (2016).

4. Latsch R., Anken T., Herzog C., Sauter J. Controlling Rumex Obtusifolius by Means of Hot Water. Weed Research 57(1):16-24 (2017).

5. Baerveldt S., Ascard J. Effect of Soil Cover on Weeds. Biological Agriculture and Horticulture 17(2):101-111 (1999). 